\title{
DESIGNING AND DELIVERING A PROGRAMME OF READING SKILLS CLASSES TO POSTGRADUATE STUDENTS
}

\author{
Christine Bohlander, Alexander Burdumy \\ Durham University \\ Phone: +4401913344678, +4419133442248 \\ E-Mail: christine.bohlander@durham.ac.uk, alexander.burdumy@durham.ac.uk
}

\begin{abstract}
Exclusively teaching the receptive skill of reading texts in a foreign language with no training in language production might seem to be a pedagogical relic and to contradict the communicative approach in foreign language teaching. However, it is a much-needed pedagogical tool for equipping postgraduate researchers with the necessary skill of reading academic literature in a foreign language. The aim is to enable learners who frequently have no prior knowledge of the language in a short period of time to independently read texts specific to their research.

This article aims to illustrate the challenges of developing face-to-face as well as online courses for the specific purpose of teaching reading skills in German and other languages to postgraduate students at Durham University and to discuss the underlying pedagogy thereof. After giving a short history of how these courses were set up at Durham University, we will state the aims and intended learning outcomes of a reading skills course and describe the pedagogical peculiarities and challenges that such courses entail, underpinned by educational theory. We will discuss the issue of vocabulary acquisition, offering practical solutions, and give concrete examples of the materials used, including online resources and materials specifically created by the tutors, as well as pointing out the strengths and weaknesses of the German textbooks currently available. We will share our experience in the classroom, with online teaching as well as our provision for self-study. At the end of the paper we will include links to some free online resources for primarily German and French.

This paper aims to contribute to the continuing dissemination of good practice in the teaching of reading skills in German, which can also be transferred to other Western European languages.
\end{abstract}

Key words: language learning, reading skills, German, pedagogy, reading classes

\section{HISTORY}

After delivering a successful 10-week pilot class for reading skills in German at beginners' level for researchers in the History Department in 2009, the Centre for Foreign Language Study at Durham University was asked by the Graduate School to roll out a university-wide programme of reading skills courses for postgraduate researchers and to extend the programme first to French and later to Italian and Spanish and also to intermediate and advanced levels. Since then there has been a constant high demand for German and French, particularly at beginners' level. Additionally, other languages are offered when the need arises. 
Most classes follow a format of 9 weeks per term. Two teaching hours and two to three hours of self-study are allocated per week. Students typically progress from no prior knowledge to post-beginners and intermediate levels within one academic year.

For German, most researchers in need of reading skills come from an Arts \& Humanities background with theologians forming the biggest group, followed by Classicists, Historians and Philosophers (in French the situation is similar).

Since 2010 reading skills courses in German and French have been offered as elective credit-bearing modules (30 credits) to MA students for whom the ability to read German is considered important (e.g. History, Classics, Theology). The languages offered - alongside Latin - are French and German at beginners' and advanced levels. Assessment for beginners consists of two exams (one in January and one in May/June), for advanced students it consists of a reflective online portfolio in January and an exam in May/June.

The offer of these credit-bearing language modules is seen as a competitive advantage. The History Department now prides itself in advertising its MA modules with a strong (in some cases compulsory) language strand and thereby also attracts overseas students.

\section{PEDAGOGY OF READING Classes}

\subsection{Aims}

The pedagogical challenge that an educator faces when teaching reading skills is the need to throw overboard the pedagogy of the communicative language approach, whose aim is to enable students to communicate effectively and to learn the four skills of reading, writing, listening and speaking without particular emphasis on grammar teaching as this was thought to be dated (for a definition of communicative-based language teaching and the difference between communicative and grammar competence, see Richards 2006, 2-3). The aim of the reading skills classes is for students to reach a high competency level in only one skill, i.e. reading, in a very short time. After 10 weeks, students are expected to be able to understand, for example, complex articles in quality press publications on familiar topics with the help of a dictionary, but they would not be able to order food in a restaurant or buy a train ticket. Looking at this through the lens of constructive alignment (Biggs and Tang 2011, 95), it becomes clear that the structure of a reading skills course has to be very different from a normal language class, as the learning outcomes differ greatly. For example, the learning outcome of being able to recognise different cases or endings in German is a much easier goal than producing them. On the other hand, sentences have to be looked at in greater detail so that nuances are not lost.

\subsection{Pedagogy in the classroom}

Although called a passive or receptive skill, understanding (and thus reading) is an active, productive and constructive mental process or an interactive process between data and a cognitive structure. For example, we are able to fill information gaps in a text thanks to our linguistic and situational knowledge. This top-down processing controlled by our knowledge (e.g. contextual information) as opposed to the bottom-up approach controlled by data (e.g. word by word) is the basis for our pedagogy in the classroom, as supported by Storch's (1999) notion on the understanding of texts.

The concept is best understood if compared to the teaching of Latin or ancient Greek. At first sight, the pedagogic approach looks very old-fashioned like in the olden days 
when students learned the grammar and the structure of a language in a more academic way rather than communicative skills as is the case nowadays. We would argue, however, that we clearly follow a constructivist approach where we help students to construct their own knowledge, albeit receptive knowledge, on how to deconstruct a written text. Right from the beginning the students will be confronted with texts, whether they are "authentic" texts by other authors or texts adapted for use in textbooks or learning materials in order to explain and practise certain points about the structure or grammar of a text. The emphasis is on encouraging students to formulate hypotheses, e.g. by asking them:

- What do you guess the text is about?

- What is the gist of the text?

- Can you recognise words?

The task in class is to work out, i.e. to deduce certain vocabulary (often cognates) and structural patterns (e.g. word order, grammatical function in the clause such as verb) in pairs or small groups with the help of the teacher who will ask guiding questions. This deductive skill is practised and consolidated through self-study.

Translation tasks play a major role in assessing and advancing learner's reading skills and in training deductive skills. Each week students are asked to translate a text from German into English based on a grammar point that was introduced in class. It is important to point out that we do not teach translation skills or accuracy in English and to bear in mind that many students are non-native speakers of English. The sole purpose of the translation is to elicit whether students have understood the underlying structure of the German text. There is an important difference to the language pedagogy of translation classes. Here translation serves as a means to assess students' understanding in the reading skills class whereas in a translation module the skill of translation is the learning outcome.

Another effective way of assessing reading skills, e.g. in exams, is via multiple-choice tests. Here the afore-mentioned bottom-up approach is applied to homework and assessment. Whereas researchers must to a certain extent be able to skim-read a text in the foreign language, experience has shown that with complex texts the devil is in the details. If no attention is paid to the detailed structure of a word or sentence, this can lead to grave misunderstandings of the content of the text. The role of the teacher as facilitator of understanding, the deductive approach in class involving pair and group work and the translation task are all examples of how students are required to construct their own knowledge.

The acquisition of vocabulary is another example where the responsibility for constructing knowledge lies with the students. Each student needs to build up their own bespoke vocabulary required for their research topic, which will vary between disciplines. The students will learn the skills of how to look up words in print or in online dictionaries, and online flash cards help students learn the basic vocabulary and the most frequent forms as well as cognates and false friends. This forms a basis on which students are able to construct their own lexicon by adding specialist terminology relevant to their discipline.

According to Biggs' 3P model (1993) the students' predispositions, i.e. their presage will play an important role in the process and the product of learning and teaching. Particularly classicists who are trained in exactly these receptive linguistic skills to be able to read Latin and Greek texts have already acquired a great deal of the skills that others need to construct, albeit in a different language. It plays to their advantage that German has a similar structure regarding noun declensions to the Latin and Greek structures. At the other end of the spectrum 
there are some English native-speakers who have never learned a foreign language and who have not had grammar instruction about their own language. The teacher's task here is to guide them to recognise different parts of speech. Rote learning, which can be successful in the communicative approach up to a certain level, e.g. when you go on holiday and are able to order a drink, can only help to build up vocabulary, but unless students pass the threshold of understanding the underlying structure and grammar of a text in a foreign language, i.e. the stage of analysis in Bloom's taxonomy (Bloom 1956), they will not be able to deconstruct a text for their research independently. Meyer and Land's (2006) threshold concept framework comes to mind. It could be argued that classicists and others who have already learned a classic language (e.g. theologians who have learned biblical Greek) have already passed this threshold before starting to learn German. They only need to learn how to transfer their reading skills to another language. For other students this can be strange territory outside their comfort zone and therefore a troublesome learning journey before they manage to pass this threshold (Meyer and Land 2006). Therefore, in our experience, it can be helpful at PhD level if the institution supports one-to-one tuition with the teacher or a mentor. The students will bring in their own texts and go through them with the tutor. Students often have the advantage of the specialised subject-knowledge, but often struggle with very complex texts.

Another question that sometimes arises is whether pronunciation is important for reading skills or not. We do teach pronunciation in the first session for two reasons:

a) When we read texts silently, we still pronounce the words in our heads;

b) When students know the basic pronunciation rules, particularly of the vowels, it is easier for them to recognise cognates such as Wein (as opposed to Wien), Haus or Vater.

That said, it would be counter-productive to have students read out texts in class.

The model created for the German reading skills classes was rolled out to French, Spanish and Italian. Non-European language classes were also offered, but after an initial discussion it was established that the approach needed to be different for languages with a different script and grammar structure. For this reason, an attempt to create a generic template for all languages was eventually discarded.

\section{READING SKILLS TEACHING AND LEARNING RESOURCES}

In general, the specialised nature of reading skills means that resources need to be specifically tailored for the training of reading skills and that the vast amount of readily available course books and exercise material for "normal" language learning purposes has very limited use for reading skills. Grammar explanations need to be in English, written with the aim that the learner will understand grammatical structures and features, their recurrence and their implication for meaning, while using a dictionary as a resource for vocabulary. As a result, typical grammar books intended for learners who also engage in language production (speaking and writing) are not recommended for the purpose of developing German reading skills. Practice material needs to be tailored to test the understanding of the acquired grammar knowledge in a way that allows the learner to gain confidence in their receptive and deductive skills. When working with (preferably authentic) texts, the focus needs to be on the understanding of content, deductive logic and the ability to identify grammatical structures and to make sense of them, rather than simple translation. The majority of practice material in course books is aimed at language 
production for communicative purposes rather than the understanding of texts, which means that exercises must be designed specifically for reading skills and the proficiency level of the students.

As a result, the main criteria for resources designed explicitly for reading skills, are:

- The quality of the explanation of grammar points: How accessible and useful are these? Are there useful hints and recommendations, or is the material presented very dry and abstract? The presentation of the material should start from the viewpoint of how grammar presents itself in authentic texts (and not in grammar books!) and focus only on what reading skills learners need to know, rather than taking a holistic approach. For example, learners need to be able to identify if an adjectival form is used as an adjective or an adverb in German, but they do not need to learn adjective endings by heart.

- The amount of relevant practice and whether there is enough of it. Ideally, every grammatical point should have one exercise along with it and a more overarching exercise or text to practise several grammatical points in a formative way.

- Whether the resource is made for self-study use or for use in a taught course will be of interest to most learners. Fortunately, course books for reading skills tend to cover both or can at least be easily adapted to taught courses.

- Finally, it should also be considered how well it can be used for revision purposes. Many learners will have learned some German at some stage, but often have not practised the language for a significant amount of time and are therefore looking for revision and guidance material.

\subsection{Currently available material}

There are a number of books written specifically for acquiring reading skills. In many ways these represent the easiest and most promising path to successful learning, as they were written with a clear goal in mind and cover all the criteria listed above. At the time of writing (January 2018), however, only two such volumes were readily available in the UK and/or at a reasonable price (approximately £30). The most accessible book, April Wilson's German Quickly. A Grammar for Reading German (2007) may be over 10 years old, but is still in many ways the freshest and most straightforward entry to acquiring German for reading purposes. As the name implies, chapters are ordered along grammar points, with the practice material becoming gradually more difficult. The volume has two weak points: first, the order of chapters is debatable, with reflexive verbs and passive voice being relatively late, and as such the exercises are quite hard (if previous chapters are skipped). Second, most practice focuses on short sentences, which, while being sensible practice, does not give learners the depth and challenge of working with longer texts. The book is very light on the training of understanding and deductive skills and rather focuses on grammatical points. However, despite these drawbacks, it is the most recommended resource for students looking for an accessible self-study book; it can be adapted for use in taught courses as well, with some work. Among its strengths are its completeness (it even includes a useful vocabulary section based on subjects from Humanities), its availability and price (in the UK) and the accessible pedagogical approach used within. It is also very easily used as a revision tool for those looking to brush up on their German.

The other book that is widely available in the UK, Reading German. A Course Book and Reference Grammar (1997) by Waltraud Coles and Bill Dodd is older (the 2009 and 2006 
versions are reprints of the 1997 original) and does not take into account the 1996 spelling reform. The content is organised along a logical progression path, rather than grammar points, and while this works better for taught courses, it makes it less accessible for self-study, especially since many grammar points are only explained briefly in the chapters in the front and charts and further information is located in the back of the book. In addition, the explanations and approach on how to deal with the German case system - the most difficult part of German grammar - are a major weak point in this volume. One of the strengths of Reading German is, however, the large amount of practice texts, even if the longer practice texts and comprehension questions are not as challenging as the authors claim; the book is comparatively better at training deductive reasoning skills than German Quickly.

Richard Alan Korb's German for Reading Knowledge. $7^{\text {th }}$ ed (2014) is the latest version of Hubert Jannach's German for Reading Knowledge. $3^{\text {rd }}$ ed (1980). Second hand versions of the $3^{\text {rd }}$ ed. are sometimes available, but not recommended over the $7^{\text {th }}$ ed. The $7^{\text {th }}$ ed. is in general a good resource and can be used for both self-study or, with adaption, as a course book. The book occupies the middle ground between German Quickly and Reading German. It is organised along grammar points, rather than a natural progression. Its strongest feature is the large selection of very useful and varied practice texts. It also features a list of selected vocabulary after each chapter. The drawback is that some of the grammar explanations are not as easily understood (or useful) as those in the aforementioned books. In addition, online reviews of it are mixed and different editions of the later versions $\left(5^{\text {th }}, 6^{\text {th }}, 7^{\text {th }}\right)$ seem to have a different page layout, which would necessitate all learners to have the same edition if used as a course book. It is not readily available in the UK and imported copies are costly.

Finally, there is Karl Sandberg and John R. Wendel's German for Reading (1973 and 2015). Only the 1973 version was available for review, which is focused on self-study and uses an interesting system for memorisation of words, phrases and grammar. At the time of writing only used copies of the 2015 version were available in the UK at comparatively high prices, suggesting that this version is currently out of print.

\subsection{Online resources}

In addition to printed material, there is some online material available. While the Learning Object Creator database (LOC) at the time of writing, had only three entries related to reading skills (and one resource, a text by Karl Marx, appears to have some broken links) and Humbox had only one, the use of these platforms could increase in the future with more material being uploaded. Several universities in the UK have also put in place online resources to support learners at their institutions in their learning aim. The Language Centre at the University of Cambridge has material available on their Language Centre/Open Courseware webpage.

Durham University has created online reading courses for researchers in German and French. The target audience are researchers with or without prior knowledge of the foreign language. Instead of presenting users with the grammar first and then exposing them to a text, the underlying pedagogy for the German module is to have students analyse and deconstruct (authentic) texts from the start, i.e. the aforementioned top-down approach. The modular approach allows students with prior knowledge to choose the sections that are relevant to them. The aforementioned resource about a text by Karl Marx is also integrated in the online reading course. 


\subsection{Modes of learning}

As hinted in the text above, a large proportion of learners opt for a self-study approach. In many cases, this is driven by either time constraints or the fact that there is no taught course available to them. At the time of writing, only a handful of UK Higher Education Institutions have consistent levels of demand by researchers to offer taught modules in reading skills on a regular basis: Cambridge, Durham, Exeter, KCL and Oxford. Manchester, Bristol and Nottingham have offered taught courses on occasion, but not on a regular basis, and some universities such as Birmingham and Warwick used to run taught courses, but have not done so for several years. The specialised nature of reading skills means that the target group of learners is naturally very small - mostly researchers from specific fields - and this often makes taught modules either financially unfeasible or it makes it difficult to anticipate demand. In June/July 2017, Durham University piloted a new distance-learning approach within the Northern Bridge Doctoral Training Partnership to offer reading skills to $\mathrm{PhD}$ students enrolled at Durham University, Newcastle University and Queen's University Belfast. The course was taught through Adobe Connect (a conference software package) to 7 students for 10 weeks and covered a beginners' level of reading skills. A custom-written dossier was used as an electronic course book, which guided students through grammar sections along with exercises. The nature of the distancelearning approach meant that progress was slightly slower than in courses taught in class, and that the interaction between learners and teacher was more limited. However, the big advantage over a purely self-study approach was that learners could give direct feedback on their learning progress to the teacher by asking questions, verifying statements and requesting further practice on particular items. The student feedback was excellent and a second course is already in the planning for 2018. As such, the distance-learning mode represents a solution to provide more universities with the ability to offer reading skills courses to their students, even if demand fluctuates and the universities cannot supply the staff to teach such a course on a regular basis.

\section{CONCLUSION}

This paper has outlined the learning and teaching processes that have been successfully implemented for the acquisition of reading skills for postgraduate researchers at Durham University. Over the years, student feedback and teacher experience have informed our understanding of the subject and allowed us to refine our approach. The needs of researchers - to quickly attain a level of skill that will allow them to read German texts efficiently - are met by this approach.

We have highlighted the differences to a typical language class based on the communicative language teaching approach, such as the tasks used in the class, the differences in the design/availability of materials and resources, and the skills that are trained. Especially vocabulary learning often takes a much more individual path, with students having an active role in constructing their own lexicon. 


\section{REFERENCES}

Biggs, John. "From theory to practice: a cognitive systems approach," Higher Education Research and Development 12, no 1 (1993): 73-85.

Biggs, John, and Tang, Catherine. Teaching for Quality Learning at University. Maidenhead, UK: Open University Press, 2011.

Bloom, Benjamin S. Taxonomy of educational objectives: The classification of educational goals. Handbook I: Cognitive domain. New York, Toronto: Longmans, Green, 1956.

Coles, Waltraud and Dodd, Bill. Reading German. A Course Book and Reference Grammar. Oxford: Oxford University Press, 1997.

Jannach, Hubert. German for Reading Knowledge. 3rd ed. New York: D. Van Nostrand Company, 1980.

Korb, Richard Alan. German for Reading Knowledge. 7th ed. Belmont: Heinle, 2014.

Meyer, Jan and Land, Ray. Overcoming barriers to student understanding: Threshold concepts and troublesome knowledge. London: Routledge, 2006.

Richards, Jack C. Communicative Language Teaching Today. New York: Cambridge University Press, 2006.

Sandberg, Karl C. and Wendel, John R. German for Reading. Englewood Cliffs: PrenticeHall, 1973.

Sandberg, Karl C. and Wendel, John R. German for Reading. $2^{\text {nd }}$ ed. Indianapolis: Hackett Publishing Company, 2015.

Storch, Günther. Deutsch als Fremdsprache: eine Didaktik: theoretische Grundlagen und praktische Unterrichtsgestaltung (Vol. 8184). Paderborn: Fink, 1999.

Wilson, April. German Quickly. A Grammar for Reading German. Revised ed. New York: Peter Lang, 2007.

\section{ONLINE RESOURCES}

Durham University resources (suitable for learners of any level, including beginners):

French reading skills course: http://eserve.org.uk/lire/

German reading skills course: https://duo.dur.ac.uk/bbcswebdav/xid-11081591_3

Also integrated in the above course:

How to use online dictionaries Part 1: http://loc.llas.ac.uk/lob/197/standalone/index.html How to use online dictionaries Part 2: http://loc.llas.ac.uk/lob/160/standalone/index.html The text by Karl Marx is found here:

https://duo.dur.ac.uk/bbcswebdav/orgs/X_LANGUAGE_READING/Learning\%20object \%20German/Learning\%20Object/KarlMarx/index.html

University of Cambridge resources (note that these resources are not suitable for beginners):

German academic reading:

http://www.langcen.cam.ac.uk/lc/opencourseware/german/german.html

French academic reading:

http://www.langcen.cam.ac.uk/lc/opencourseware/french/flo/french-lo.html

Spanish academic reading:

http://www.langcen.cam.ac.uk/lc/opencourseware/spanish/slo/spanish-lo.html

Italian academic reading: http://www.langcen.cam.ac.uk/lc/opencourseware/italian/italian.html

Developed by Christine Eckhard-Black from the University of Oxford: Faux amis (German): http://loc.llas.ac.uk/lob/214/standalone/index.html 